\title{
ВКЛАД ЛАТВИЙСКОГО ГЕПАТОЛОГИЧЕСКОГО ЦЕНТРА В ОСНОВНЫЕ НАПРАВЛЕНИЯ РАЗВИТИЯ СОВРЕМЕННОЙ ГЕПАТОЛОГИИ
}

\author{
Выступление нацеремонии вручения Награды Паула Страдыня \\ 12 февраля 2004 года
}

\begin{abstract}
Daži vārdi par akadēmiḳi Anatoliju B|̧ugeru
Profesors Anatolijs Blugers ir viena no spožākajām zvaigznēm pie Latvijas medicīnas debesīm.

Pats svarīgākais no dzīvē padarītā ir viṇa vairāk kā piecdesmit gadu garumā izārstētie pacienti. Ne mazāk nozīmīgi ir izaudzinātie skolnieki un loti svarīgas ir sarakstītās grāmatas, bet īpaša vieta Latvijas medicīnā ir profesora A. Blugera iedibinātai un attīstītai medicīnas nozarei hepatologijai. Apbrīnojams ir profesora redzējums nākotnē, par ko liecina tas, ka pirms vairākiem gadu desmitiem viña rakstītajās medicinas grāmatās bieži bija prognozēti fakti, kas pašreiz jau ir apstiprinājušies. Laikam jau šĩ spēja saredzēt nākotni ir |âvusi vai arī likusi profesoram A. Bļugeram klūt par izcilu zinātnieku, kas daudzkārt ir augstu vērtēts, piešķirot viṇam dažădas balvas un zinātniskos nosaukumus. Šḳiet, ka tagad profesors varētu vienkārši baudīt savas slavas apliecinājumus, bet viṇa raksturs ir citāds tikai uz priekšu! - un tādē| regulāri top jauni raksti, tiek fundamentāli izzinātas medicīnas aktualitātes, ārstēti slimnieki; vienīgi mazāk laika atvēlēts skolniekiem. Šajā profesoram tik nozīmīgā dienā sakām mūsu Skolotājam lielu paldies un vēlam arī turpmāk labu veselîbu, daudz energíjas un ilgus gadus radoša darba!

Profesore Ludmila Vīksna
\end{abstract}

Прежде всего, позвольте мне сердечно поблагодарить всех тех, кто причастен к выдвижению моей кандидатуры и присуждению мне Награды, носящей имя замечательного ученого, врачаи человека профессора Паула Страдыня. Я благодарен президиуму Латвийской Академии наук, членом которой я имею честь состоять более 30 лет, и ее президенту академику Янису Страдыню. Я благодарю ректора Рижского университета Страдыня профессора Яниса Ветру, сенат этого университета в лице его председателя академика Юлия Аншелевича. Благодарю Латвийскую Ассоциацию инфектологов и ее 
председателя члена Латвийской Академии наук профессора Людмилу Виксну и сердечно благодарю директора Музея истории медицины имени Паула Страдыня доктора медицины Карла Арона.

Наконец я хочу поблагодарить всех сидящих в этом зале, нашедших время почтить своим присутствием сегодняшнее важное и значимое для меня событие. Задолгие годы моей врачебной и научной деятельности я был удостоен многими премиями и наградами, в том числе Государственной премией, Премией Совета министров, именных премий (в том числе Премии имени Боткина Российской Академии медицинских наук и рядадругих).

Но в силу ряда объективных и субъективныг причин сегодняшняя моя награда-Наградаимени ПаулаСтрадыня - имеет особый смысл, является особо значимой и ценной. И связано это, с одной стороны, с тем глубоким уважением, которое я питаю к личности этого замечательного человека, и с друтойс тем, что волею судьбы профессор Страдынь имел определенное отношение к моей научной карьере, сыграл значительную роль в том, что онасостоялась. Я имею в виду его участие в судьбе моей диссертации. Дело было почти 50 лет тому назад, в апреле 1956 года, когда в силу ряда сложившихся для меня неблагоприятных обстоятельств, очень трудно проходилазащитадиссертации и неизвестен был исход ее. Выступление тогда на защите профессора Паула Страдыня, который дал высокую оценку моей работе, сыграло решаюшую роль в положительном исходе защиты, а в дальнейшем и положительную роль в моей судьбе в науке, в частности, в приеме меня напреподавательскую должность в Рижский Медицинский институт.

К творчеству этого замечательного ученого мне пришлось прикоснуться дважды. Первый раз в 1960 году, когда мы совместно с академиком Максом Беленьким обобщали труды профессора Страдыня в области клинической и экспериментальной фармакологии и столкнулись с тем, что и в этой области, которая, казалось бы лежалане в русле столбовой дороги его деятельности (я имею в виду хирургию, онкологию или историю медицины), профессор обогатил науку значительными, весьмаценными работами по изысканию и изучению новых лекарственных препаратов. Профессор был пионером в изучении, созданных академиком Соломоном Гиллером и его сотрудниками новых классов химиотерапевтических препаратов - нитрофуранов в хирургии и тиотефа в онкологической практике. И есть справедливое основание считать, что профессор Страдынь заложил основы целого, нового направления медицины в нашей республике - химиотерапии опухолей.

Второй раз мне пришлось принять участие в работе над одним из достаточно полных, хотя и кратким, научно-биографическим очерком о жизни и деятельности ученого. Основным автором этой статьи был академик Янис Страдынь. И я должен сказать, что меня, как и каждого, кто был знаком с деятельностью Паула Страдыня, буквально поразили и широта, и размах его научных интересов и в еще большей степени объем и многогранность общественной деятельности ученого, который одновременно успешно 


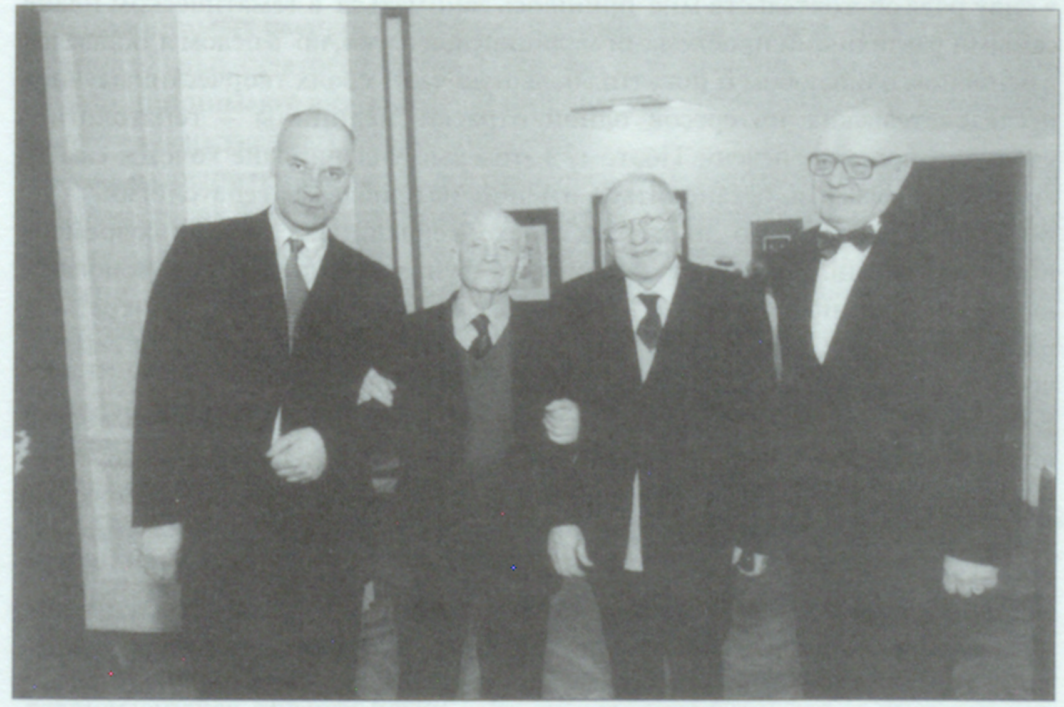

После церемонии вручения Награды Паула Страдыня: слева на право - ректор РСУ Янис Ветра, лауреат Награды профессор Анатолий Блюгер, президент Латвийской АН Янис Страдыньш и директор Музея истории медицины им. Паула Страдыня Карлис Эрикс Аронс.

Рига, 12-го февраля 2004 года 
выполнял буквально десятки научно-организационных, административных и общественных обязанностей на многих своих постах.

Все это я упомянул лишь с одной целью: еще и еще раз подчеркнуть ценность и значимость для меня, и я бы сказал - престижность, полученной сегодня награды имени этого замечательного человека.

Переходя непосредственно к теме моего выступления, хочу сказать, что, хотя в силу ряда обстоятельств мне пришлось заниматься в тематическом плане самыми различными проблемами медицинской науки, но в целом я оставался в основном однолюбом и посвятил большую часть своих творческих научноисследовательских интересов одной отрасли медицины - гепатологии, учению о болезнях печени. Поэтому в этом выступлении мне хочется сжато, крупными мазками, остановиться именно напроблемах гепатологии.

Во-первых, рассказать о движущих силах и тенденциях развития современной гепатологии. Во-вторых, обозначить фундаментальные, основополагающие события, происшедшие в гепатологии в последние годы. И, в-третьих, рассказать о том, как к этим проблемам приобщился Латвийский Гепатологический центр, какую роль он сыграл в их решении.

Если годом рождения гепатологии считают 1861 год, когдапоявилась первая книга по клинике болезней печени, принадлежащая перу немецкого терапевта ТеодораФрериха, то современная гепатология началаформироваться менее чем полвека назад. Тогда, в 1957 году, вышло классическое руководство Ганса Поппера и Фентона Шафнера "The Liver: Structure and Functions". Этакнига, основываясь наданных прижизненного изучения тканей печени, оказалареволюционное, поворотное влияние на весь прогресс гепатологии. Значение этой книги для гепатологии сравнимо со значением для медицины целлюлярной патологии Рудольфа Вирхова. Использование морфологического принципастало основным рычагом быстрого прогрессаучения о болезнях печени и желчных путей.

Другой движущей силой, обеспечившей прогресс гепатологии, стал возросший социальный заказ 50-60-х годов XX века, обусловленный все расширяющимся распространением болезней печени, все возрастающим значением их в патологии человека в качестве причины заболеваемости, инвалидности и смертности.

Приведу данные, характеризующие высокую заболеваемость болезнями печени. Половинанаселения является носителями желчных камней, 2 миллиарда инфицированы $H B V$ инфекцией, 900 миллионов людей страдает хронической $H B V$ и $H C V$ инфекцией, более 1 миллиардапоражены алкогольным и неалкогольным стеатогепатитом, 180 миллионов - циррозами печени, 120 миллионов - лекарственными поражениями печени. Эти цифры заставляют вспомнить черный юмор, когда-то высказанный в отношении остеохондроза: человечество делится надве половины - однауже болеет им, другой-предстоит заболеть. Где причины такой высокой заболеваемости болезнями печени и желчньх путей? Имеется ряд постоянно действующих факторов, которые поддерживают 
высокий уровень заболеваемости, поставляют эти поражения печени. О вирусных гепатитах я уже говорил. Напомню вам: 40-75\% - пьющих людей, $15 \%$ - злоупотребляющих алкоголем, 30-60\% - избыточно питающихся, переедающих, до $25 \%$ - страдающих ожирением, 800 миллионов голодающих (это данные сентябрьской конференции в Африке по экологии). Алкоголь, нарушения питания и диабет (4-7\% населения) - это и есть поставщики самых распространенных патологических форм - алкогольных и неалкогольных стеатогепатитов. Наконец, 42\% населения хронически, длительно принимают различные лекарственные препараты. Это объясняет частоту лекарственных поражений печени.

Сейчас разрешите мне немного отвлечься от гепатологических проблем и в частности от фундаментальных открытий в этой области, и в двух словах рассказать о Латвийском Гепатологическом центре (ЛГЦ), поскольку именно создание в Риге такого центрав 1965 году позволило латвийским гепатологам достойно ответить на вызовы революционных открытий и внести свой посильный вклад в прогресс современной гепатологии.

Итак, в 1965 году на базе Кафедры инфекционных болезней Рижского Медицинского института и Республиканской клинической инфекционной больницы, повинуясь требованиям времени (я имею в виду и рост, и распространенность болезней печени, и открывшиеся новые возможности для их диагностики и лечения) был создан ЛГЦ. В нем были сформированы все лабораторные структуры, необходимые для всестороннего изучения клиники и патологии болезней печени, и таким путем созданы все возможности приобщиться к решению все нарастающего потока проблем в этой развивающейся области науки.

ЛГЦ выполнял ряд тесно связанных между собой задач: научно-исследовательские, учебно-педагогические и научно-организационные. Главной же задачей ЛГЦ всегда оставалось оказание лечебно-консультативной помощи печеночным больным, прежде всего в Латвии, а также и заее пределами. В связи с растущими потребностями в гепатологических исследованиях и, конечно, в медицинской помощи печеночным больным ЛГЦ быстро рос и развивался, и уже к 1975-му году в нем работал большой творческий коллектив, насчитывающий 80 профессоров, докторов наук, научных сотрудников. Достаточно успешно в ЛГЦ готовили кадры. За 25 лет на его базе было подготовлено и защищено более 100 диссертаций. Набазе центрабыл организован постоянно действующий цикл усовершенствования профессоров и преподавателей медицинских вузов, научных сотрудников НИИ и врачей по гепатологии, накотором прошли подготовку и обрели профессиональные знания более 500 специалистов - всего 14 выпусков по 30-35 человек из всех бывших союзных республик, а также из стран Восточной Европы.

Центр планомерно выполнял научно-организационную работу: провел пять Международных симпозиумов, четыре конференции по клинической биохимии, морфологии и иммунологии болезней печени. На базе центра в 
течение 15 лет издавался международный ежегодник “Успехи гепатологии". Издано несколько руководств для врачей и студентов - "Основы гепатологии", "Практическая гепатология" и другие.

Один аспект деятельности ЛГЦ подчеркну особо - это возможность оказывать на уровне мировых стандартов лечебно-диагностическую помощь гепатологическим больным прежде всего Латвии, а также многих других городов бывшего Советского Союза.

Мне приходится в силу ряда обстоятельств ежегодно бывать в США, где я посещаю разные гепатологические центры, в том числе и в Нью-Йорке самый крупный в мире гепатологический центр в Госпитале Синайской горы, где когда-то проводил свои революционные исследования основоположник современной гепатологии Ганс Поппер. Так вот, могу заверить вас в том, что уровень диагностики и лечения в ЛГЦ ничем не отличается от такового в известных гепатологических центрах США.

В этой связи я хочу поблагодарить своих ближайших учеников - руководителя ЛГЦ членаЛатвийской Академии наук профессораЛюдмилу Виксну, руководителя Латвийского Центра инфектологии профессора Байбу Розентале, ведущего специалиста центра профессора Язепа Кейша. Они сумели до сих пор сохранить традиции и удерживать высокий уровень деятельности центрапо оказанию помощи гепатологическим больным.

Теперь, в заключительной части моего выступления, назову вам те фундаментальныя события в современной гепатологии, которые произошли во второй половине XX столетия и которые преобразили эту науку. В английской литературе их называют Landmark, что ознает поворотные пункты гепатологии.

1. Разработкатехники биопсии печени G. Menghini (1957), которая положила начало прижизненной морфологии печени (H. Popper, 1957).

2. Открытие феноменагиперферментемии, т.е. повышение активности АЛАТ и $\operatorname{ACAT}(F$. Wroblewski, 1956).

3. Идентификация возбудителей вирусных гепатитов - HBV (B. Blumberg, 1962).

4. Разработкаэффективных методов лечения хронических прогрессирующих болезней печени. Успехи интерфероно-рибаверинотерапии вирусных reпатитов $C$ и $B$.

5. Трансплантация печени (T. Starzl, 1963).

6. Открытие молекулярных механизмов наследственных болезней печени гемохроматозаи болезни Вильсона(M. Simon, P. Brissot, 1988; Y. Yamaguchi, 1983).

Как же откликнулся наэти события ЛГЦ, какой вклад внес в новые направления, определившие прогресс гепатологии?

Как только появились исследования Попперапо прижизненной морфологии печени, мы в ЛГЦ довольно быстро к ним приобщились. Метод пункционной биопсии быстро и успешно освоили в ЛГЦ. Необходимо в этой связи 
подчеркнуть, что сейчас центр обладает одним из самых крупных архивов морфологических препаратов - его коллекция насчитывает более 10 тысяч образцов. Что же дает этот метод? Он позволил обнаружить, что под маской одной и той же монотонной клинической картины скрываются десятки различных по природе и прогнозу болезней печени. Приведу всего один пример. Под “маской” лекарственного гепатита могут протекать шесть совершенно различных видов морфологического поражения печени. Хорошо иллюстрирует значимость прижизненного морфологического исследования печени и такой пример: если в 50-е годы XX века в гепатологии были известны 30 нозологических единиц, то через три десятилетия эта цифра утроилась, и современные руководства содержат более 90 печеночных болезней и синдромов.

Не менее важно и то, что прижизненная морфология устранила многие ошибки и заблуждения прежней гепатологии, базировавшейся на данных аутопсии. Дело в том, что сразу после смерти гепатоциты быстро подвергаются аутолизу, что резко искажает морфологическую картину. Мы столкнулись с этим сразу же после первых прижизненных пункций печени. На протяжении сталет в медицине бытовало заблуждение, что при вирусных гепатитах из гепатоцитов исчезает гликоген и они становятся ареной для жировой инфильтрации. На этих данных и основывалось годами применявшееся лечение таких больных: введение концентрированных растворов глюкозы и инсулина с тем, чтобы восстановить в печени запасы гликогена. Результаты же первых пункций печени опровергли это заблуждение: оказалось, что даже при самых тяжелых формах вирусных гепатитов в гепатоцитах полностью сохранен гликоген и нет никаких признаков жировой инфильтрации. Вместо этого мы увидели выраженные нарушения белковой структуры, т.е., белковую дистрофию.

Подобных примеров пересмотра прежних, казалось бы, незыблемых взглядов тогда оказалось много. И прижизненное морфологическое изучение ткани печени стало центральным в работе ЛГЦ. Уже в 1962 году вышла наша совместная с доктором медицинских наук Марией Синельниковой первая монография по этому вопросу, аеще через год ему былапосвящена моя докторская диссертация "Структураи фикции печени при эпидемическом гепатите", такое название которой я дал не без влияния классической работы Г. Поппера.

В 1964 году в Латвии вышел первый в то время “Атлас электронной микроскопии печени", а в конце 80-х годов в Риге была издана подготовленная нами совместно с сотрудниками отдела морфологии - ныне покойной профессором Ольгой Карташовой и присутствующими здесь, в зале, докторами наук Валентиной Залцмане и Натальей Макаровой - монография "Ультраструктурная патология печени".

Вторым крупным открытием в гепатологии стало обнаружение Феликсом Вроблевским и Ла Дю в 1956 году при поражении печени феномена 
гиперферментемии, т.е. повышение в сыворотке крови активности ферментов, содержащихся в гепатоцитах, трансаминаз, или аминотрансаминаз. Перед гепатологами стал вопрос, каков механизм этого феномена?

Авторы открытия предполагали, что ферменты вытекают из гепатоцитов в кровь после некроза клетки. Посвятив в то время этому вопросу серию работ совместно с профессором М. Беленьким, мы установили, что в основе гиперферментемии лежит иной механизм. В его основе не некроз клетки, а повышение проницаемости клеточной мембраны, что и обусловливает выход ферментов в кровь. Гиперферментемия является маркером самой частой формы поражения печени - синдрома цитолиза.

Открытие Вроблевским в 1957 году феномена гиперферментемии при поражении печени потому отнесено к принципиальным фундаментальным событиям, что оно заставило пересмотреть цели и задачи функциональной диагностики болезней печени. Ранее она была направлена на тестирование бесконечного числа свойственных гепатоциту биохимических процессов: беспрерывно росло число предлагаемых проб, причем никак не увеличивалась их информативность для клиницистов. На клиницистов накатывалась лавинапроб, достигнув к 60-м годам 1000 наименований. Теперь сохранились лишь те старые пробы и брались на вооружение те новые, которые маркировали конкретные патологические процессы: цитолиз, воспаление, фиброз, стаз желчи и т.д. В результате после открытия Вроблевского на вооружении осталось 5-7 проб, необходимых и достаточных для решения большинства клинических задач; их образно называют “джентельменским" набором гепатолога.

Третье крупное открытие связано с идентификацией возбудителей вирусных гепатитов. Надо сказать, что вирусные гепатиты стояли особняком по отношению к другим вирусным инфекциям. Выделение их возбудителей задержалось почти на 50 лет по сравнению с другими инфекциями. Помог случай. Филадельфийский гематолог Барух Бламберг обнаружил в крови австралийских аборигенов какой-то чужеродный белок, назвав его австралийским антигеном. Изучая его, он установил, что этот белок является оболочкой вируса гепатита $B$.

Открытие Бламбергаимело глубоко принципиальное значение. Во-первых, оно вывело из тупика, казалось бы, неразрешимую проблему, связанную с выделением возбудителя одной из самых тяжельх форм вирусных гепатитов гепатита $B$. Развитие этих исследований завершилось разработкой новых методов диагностики этой инфекции и созданием эффективной вакцины для ее предупреждения. Таким образом, вирусный гепатит $B$ стал контролируемой инфекцией, и сейчас стала реальной задача ее ликвидации. Но самое главное то, что открытие Бламбергапривело к обнаружению нового классатак называемых медленных вирусов, вызывающих болезни с очень длительным инкубационным периодом. И еще одно свойство отличает "медленные" вирусы: они не вызывают цитолитического действия, т.е. не разрушали клетку, 
в которой паразитировали. Заоткрытие “медленных" вирусов Бламберг вместе с доктором Гайдушеком в 1976 году были удостоены Нобелевской премии. После этого открытия быстро, в течение 25-30 лет, была расшифрована почти вся азбука вирусных гепатитов. Были открыты возбудители гепатитов $A, D, E$, затем $C$ и $G$ и наконец - $T T V$.

После открытия “медленных" вирусов перед гепатологами стал важный вопрос: акаким же образом разрушаются гепатоциты, если вирус в процессе репликации не лизирует клетку, т.е. каков же патогенез вирусных гепатитов? По этому вопросу в ЛГЦ, начиная с 70-х годов, были проведены целенаправленные исследования. Во-первых, нам удалось подтвердить в культуре ткани, что внесенные в нее вирусы действительно не разрушают гепатоцитов. Было найдено, что их разрушают иммунные реакции, направленные против вируса, прежде всего это лимфоциты-киллеры и антитела против вируса. Нейтрализуя, разрушая вирусы, иммунные факторы разрушают и гепатоциты, воистину, выплескивая воду, выплескивают и ребенка. Так нами с профессором X. Векслером был описан иммунопатогенез вирусных гепатитов, была разработана и опубликована вирусно-иммуногенетическая концепция механизма патологического процесса. Кратко она сводится к тому, что при слабых реакциях возникают легкие и хронические формы болезни, при средних, нормальных - острые, циклические, а при очень сильных - иммунные факторы вызывают массивный некроз, разрушают печень, часто приводя к смерти больного. Когдаже в силу ряда причин иммунная системане реагирует, возникает пожизненное носительство вируса.

Среди вирусных гепатитов сегодня самой сложной остается проблема вирусного гепатита $C$, которым болеют в мире, по разным данным от 200 до 500 миллионов, у нас, в Латвии, - до 80 тысяч человек. Вирус гепатита $C$ принес много загадок. У него оказалась очень сложная и постоянно меняющаяся структура ядра. Эта гетерогенность и изменчивость вируса привели к одной из самых непонятных и удивительных особенностей инфекции вирус ускользает от антител и вызывает хроническое течение даже при очень высокой концентрации антител у больных. Эти свойства вируса осложняют создание вакцины против него. $80 \%$ зараженных становятся хроническими больными, у половины из них инфекция завершается циррозом и у $10-15 \%$ - раком печени.

Вирусные гепатиты на протяжении всех лет были всегда в центре нашего внимания. После открытия австралийского антигена нами была выпущена монография по этой проблеме. Регулярно, каждые 5-7 лет, мы выпускали руководство по вирусным гепатитам для врачей. И мне приятно отметить, что в прошлом году ряд этих руководств пополнился монографией моей ученицы профессора Людмилы Виксны, посвященной самой актуальной проблеме современной гепатологии - гепатиту $C$.

Четвертым крупным событием является разработка в 60-80-е годы эффективных методов лечения хронических прогрессирующих заболеваний печени. 
До этого времени по сути дела существовали иллюзорные методы, которые успешно применяли при доброкачественных, по сути не требующих лечения болезнях печени. Нааутоиммунные и вирусные прогрессирующие болезни тогдашняя терапия не оказывалаэффекта.

Дело коренным образом изменилось после предложенной иммуносупрессивной терапии: глюкокортикостероиды и азотиаприм для аутоиммунных гепатитов и противовирусной терапии гепатитов $C$ и $B$.

Я хотел бы сказать, что данные мирового опыта, атеперь уже и наши данные, свидетельствуют о том, что с открытием пролонгированных интерферонов (препараты Pegasis и Pegintrong) и их применением в комбинации с рибоверином удается излечить от хронического гепатита $C$ от 75 до $95 \%$ пациентов. К сожалению, сегодня проблемы лечения от этой коварной инфекции перешли из чисто научной плоскости в финансовую. Во всех развитых странах Европы и в США расходы на лечение этих больных берут на себя страховые компании. Увы, у нас, в Латвии, мы вынуждены ожидать лучших времен, когда изменится ситуация в стране в целом и в здравоохранении в частности.

К числу открытий в гепатологии справедливо относят и успехи в трансплантации печени. 40 лет тому назад Старзл произвел первую пересадку печени. С тех пор появились реальные возможности значительно продлить жизнь при ранее неизлечимых смертельных болезнях печени, многие из которых являются исходами вирусных гепатитов, анекоторые носят наследственный характер. Речь идет об опухолях, гепатомах и циррозах печени. Сегодня появилась возможность успешно решить всегда очень сложную проблему доноров. Речь идет об успешной пересадке части печени, полученной от родственников. Этот метод получил название Adult to adult living donor. Сейчас на 1 миллион жителей в США проводят 18 транплантаций, в Европе - 12-14, т.е. в год в мире делается 18 тысяч таких операций. Как и всюду, нуждающихся в такой операции и в Латвии предостаточно, но, конечно, при нынешней ее стоимости о трансплантации печени у гепатологических больных мы можем только строить планы на будущее.

Сейчас гепатология прочно перешлана рельсы молекулярно-биологического изучения патологии печени. Удалось раскрыть - и это последнее крупное достижение, о котором я хочу вам рассказать - молекулярные механизмы таких ранее неизвестных по природе неизлечимых или трудно поддающихся лечению прогрессирующих форм циррозапечени, как гемосидероз, связанный с отложением в печени железа, и болезнь Вильсона, обусловленную отложением в печени меди. В ЛГЦ начиная с 80 -х годов успешно использовали молекулярно-биологические методы для изучения тонких механизмов патологических процессов в печени. В частности, мне хотелось бы назвать работы, выполненные мною совместно с моей сотрудницей профессором Айей Майоре по изучению роли перекисного окисления липидов, атаки молекулярного кислорода и свободных радикалов в процессе повреждения 
мембран гепатоцитов - это основной механизм синдрома цитолиза, разрушения клетки.

Нами также были проведены исследования по изучению эффективности антиоксидантов при этих процессах. И здесь мы столкнулись с одним из нередких в патологии печени парадоксов: выраженная эффективность антиоксидантов в эксперименте, к сожалению, и это хорошо знают все гепатологи, в клинике оказалась малоощутимой. Причины этого пока не выяснены.

Свое выступление я хотелбы закончить, напомнив вам, что в печени, в патологии печени, до сих пор сохранилось много, я бы даже сказал слишком много, необъяснимых явлений, темных мест, неразгаданных парадоксов. Когда-то я написал для широкого круга читателей научно-популярную брошюру с интригующим названием “Тайны и парадоксы печени”. Думаю, что тайн и парадоксов в гепатологии хватает до сих пор, хватит их и для будущих исследований ЛГЦ, который всегда был настроен на поиск и открытие новых фактов и явлений.

Я от души хочу пожелать в этом успеха моим ученикам, перенявшим у меня эстафету, пожелать им, чтобы они успешно ее несли и передавали следующим поколениям.

\section{An Academic Speech on Receiving Pauls Stradiņš Award on the 12 of February, 2004 (Summary) \\ By Anatolijs Blugers}

The author presents this thanks to all organizations, institutions and persons who have proposed him a candidate for the Pauls Stradiņ̌s Award. He gives a brief survey of his meetings with Paul Stradinš, describe the Centre of Hepatology and its contribution to the development of modern hepatology.

Анатолий Блюгер, профессор

ablug@inbox.lv 


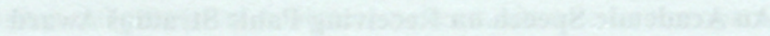

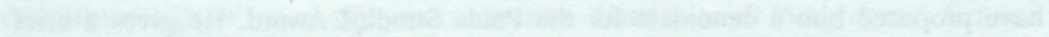

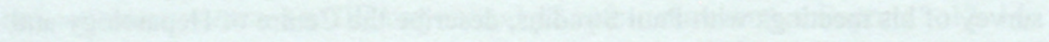

